\title{
Proceedings of the Fourth International Course on Therapeutic Endoscopy
}

$\mathrm{I}_{\mathrm{s}}^{\mathrm{N}}$ NTERVENTIONAL ENDOSCOPY HAS COME OF AGE. Scarcely more than 10 years ago, discussions about upper gastrointestinal bleeding centred around the need for diagnostic esophagogastroduodenoscopy. Now it is accepted that this procedure is necessary; in fact the present controversy is over what endoscopic technique best stops active bleeding and prevents rebleeding. Similarly, endoscopic modalities to obliterate varices have become standard treatment, and yet it was only recently written that such procedures are "Mickey Mouse te hniques which are temporizing measures at best". The term 'surgical jaundice' has literally vanished from the literature - such cases are now most commonly treated endoscopically, whereas former 'medical' causes of jaundice such as primary biliary cirrhosis have become the diseases which often benefit from surgery (liver transplantation). Moreover, it is becoming accepted that liver and pancreatic tumours that cause symptoms by luminal obstruction are at least as well palliated endoscopically as surgically.

New endoscopic techniques pose a dilemma for practising endoscopists. On the one hand, it is difficult to learn such techniques without direct guidance from experts, yet on the other hand, these rapidly become the preferred procedures for exemplary medical care. Reading about complicated methodology is rarely sufficient to allow the techniques to be mastered, even by experienced endoscopists. To resolve this problem, we have instituted a series of novel courses on therapeutic endoscopy during which physicians are able to actually watch experts carry out endoscopic maneuvres. These sessions are transmitted live so that the 'students' can observe all aspects of each technique, and watch both the successes and the failures of each attempt. Not only are new techniques and 'tricks of the trade' learned during each course, but also each endoscopist has a chance to compare his or her skills with the 'masters'. Perhaps the most valuable aspect of each course is the question period, when technical problems can be resolved by directly demonstrating - not just discussing - the answers to various methodological problems.

This special issue of The Canadian Journal of Gastroenterology contains some of the proceedings from the Fourth International Course on Therapeutic Endoscopy hosted by the Division of Gastroenterology of The Wellesley Hospital and held in Toronto, Ontario in October 1989. The articles are aimed at acquainting physicians with state-of-the-art interventional endoscopy. No attempt has been made to be comprehensive; rather, areas have been selected either because of their importance to clinical gastroenterology, or because of the recent advances made in that particular field. Many of the papers are written by the authorities who actually pioneered the techniques described. A special attempt has been made not only to describe methodology, but also to critically evaluate the benefits of each technique.

Not every endoscopist will perform every technique described in these pages, but at least a passing knowledge of such methodology is required for practising physicians in order that they be aware of the risks and benefits of all treatment options. Only with such information can clinicians make logical choices about which therapeutic intervention is best suited to their patients' problems. As organizers of the symposium, we believe that the information summarized here will lead to better patient care by making all physicians aware of the wide scope of modern endoscopy.

Norman E Marcon, Gregory Haber, Paul Kortan, Gabor Kandel The Wellesley Hospital Toronto, Ontario, Canada 


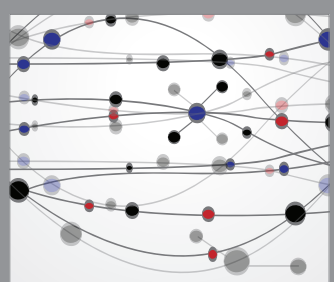

The Scientific World Journal
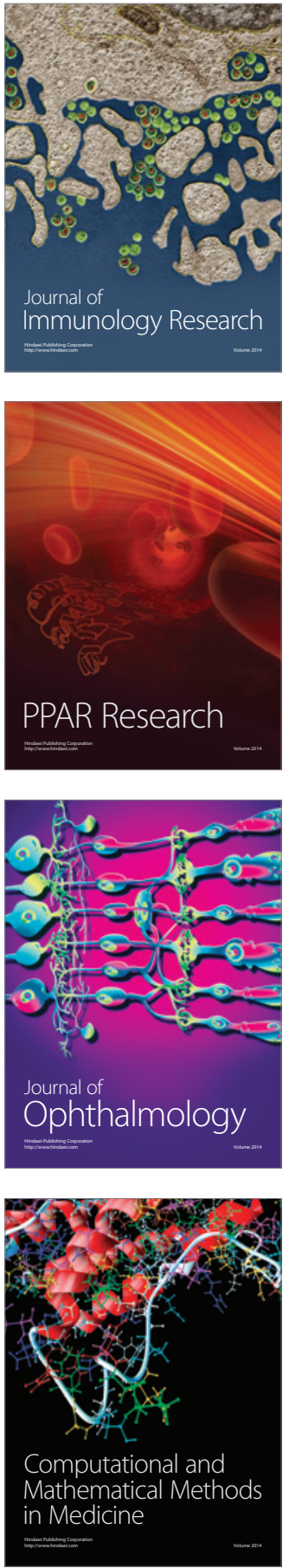

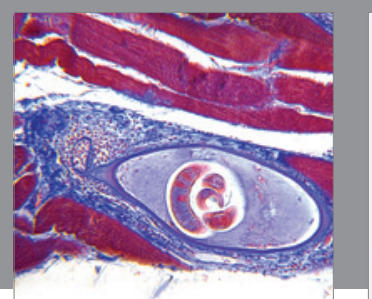

Gastroenterology Research and Practice

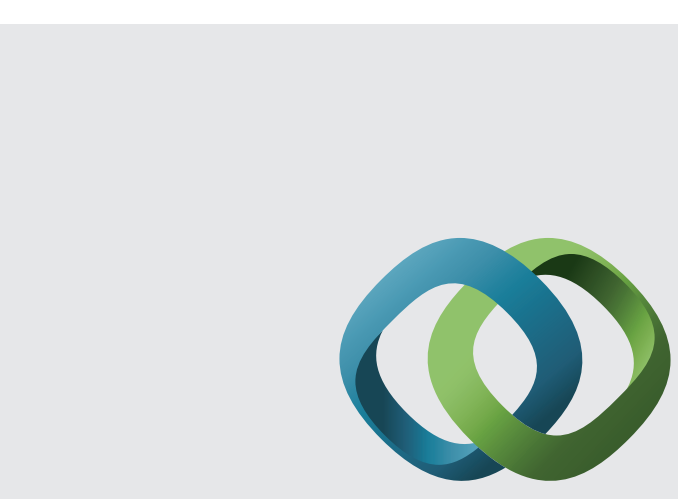

\section{Hindawi}

Submit your manuscripts at

http://www.hindawi.com
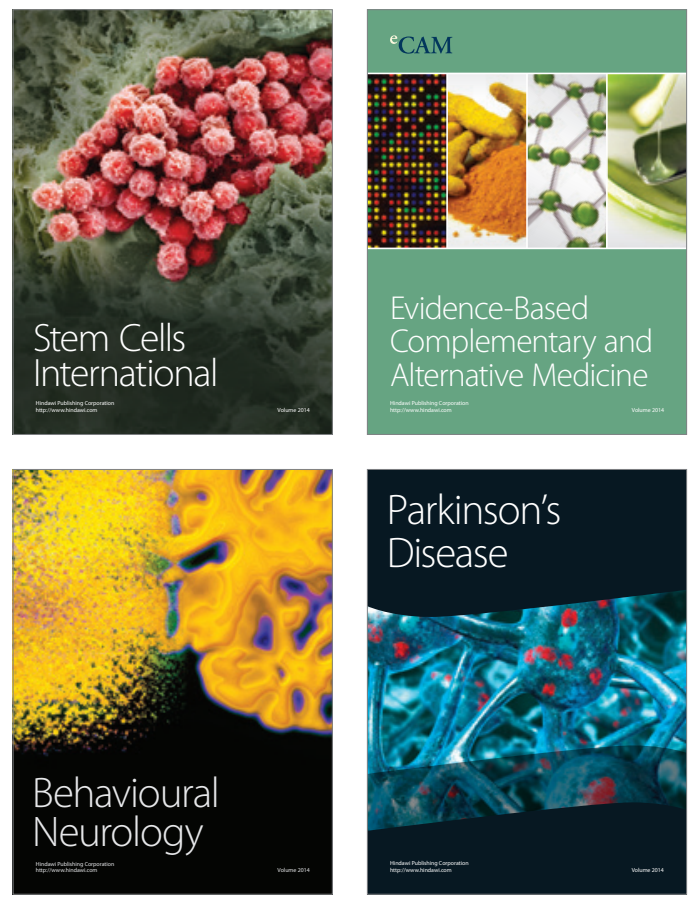
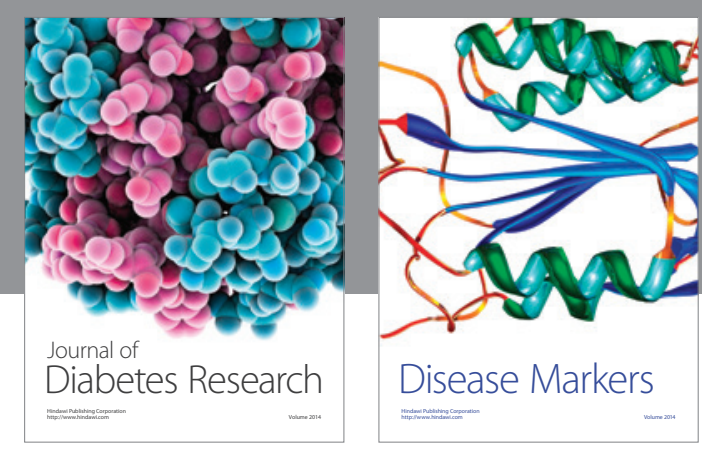

Disease Markers
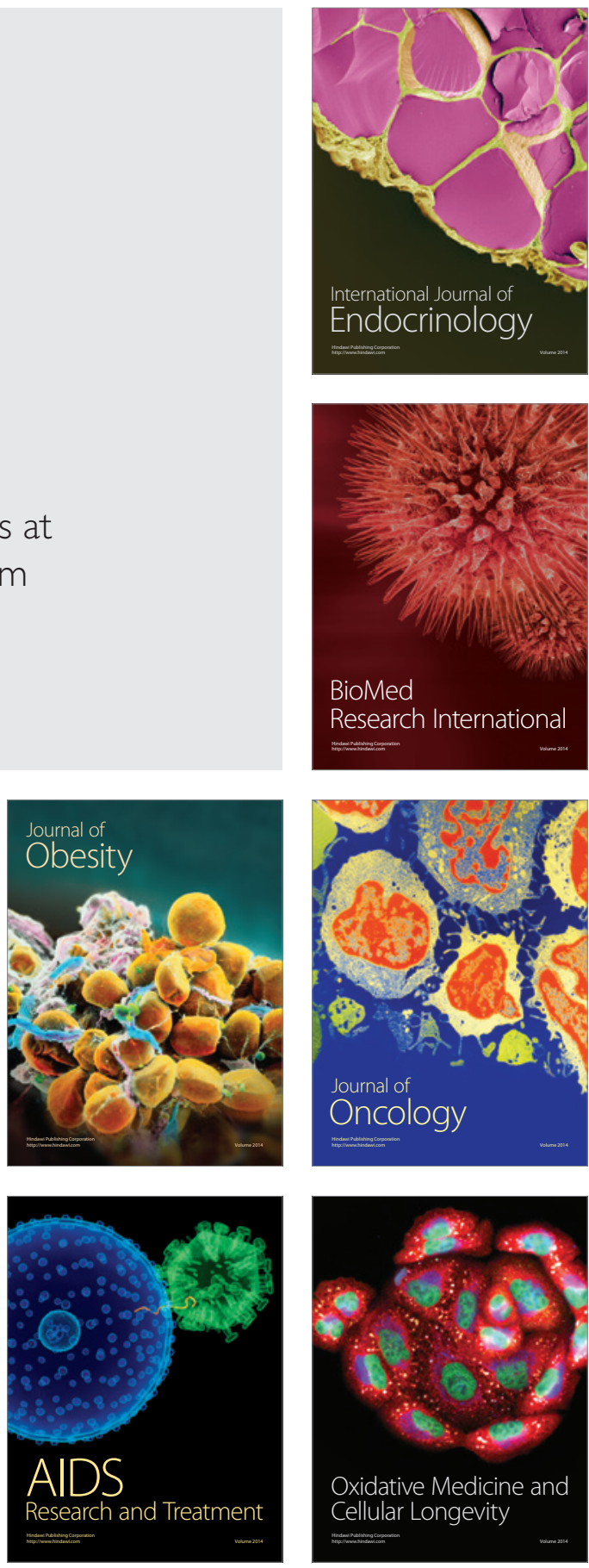